\title{
137. Simultaneous Measurement of Respiration and the Motive Force of Protoplasmic Streaming in the Myxomycete Plasmodium. V. The Effect of Carbon Monoxide*)
}

\author{
By Shigemi ABe, Hiromichi Nakajima, and Noburô KamiYa \\ Department of Biology, Faculty of Science, and Laboratory for \\ Protein Research, Osaka University \\ (Comm. by Y. KuwADA, M.J.A., Dec. 12, 1959)
}

It is well known that the respiration of many different kinds of cells is inhibited by carbon monoxide in the dark, but the inhibition is removed upon illumination with white light. This photoreversible inhibition is ascribed to a characteristic property of cytochrome oxidase contained in the cells.

The effect of $\mathrm{CO}$ on respiration of myxomycete plasmodium (Physarum polycephalum) has been studied by Allen and Price ${ }^{1)}$ and Ohta. ${ }^{2}$ Although the degree of inhibition by $\mathrm{CO}$ and the degree of reversal by light are variable according to conditions and individual properties of plasmodia, they all recognized that the respiration is inhibited considerably under a gas mixture of $95 \% \mathrm{CO}+5 \% \mathrm{O}_{2}$ in the dark, residual $\mathrm{O}_{2}$-uptake being $30-50 \%$ of the control $\left(95 \% \mathrm{~N}_{2}+\right.$ $5 \% \mathrm{O}_{2}$ ), and that the inhibition is reversed upon illumination, sometimes rather fully and sometimes only partially.

As to the protoplasmic streaming, Allen and Price ${ }^{1)}$ say, on the basis of subjective estimation, that it is not inhibited in an atmosphere of $95 \% \mathrm{CO}+5 \% \mathrm{O}_{2}$. Ohta, ${ }^{3}$ who measured the motive force of the streaming by means of the double-chamber method, also found no pronounced changes both in period and amplitude of the dynamoplasmogram.

In the present work simultaneous measurement of the motive force of the streaming and respiration was conducted under the effect of $\mathrm{CO}$ gas. The principle of the method was the same as described before. ${ }^{4)}$ The experiments were performed under two different conditions, i.e. in the dark and in the light.

a) Experiment in the dark. In order to keep the material in the dark during the experiment, the light beams from $L_{1}$ and $L_{2}$ [cf. Fig. 1 in the first report] ${ }^{4}$ illuminating the two oil drops in the glass capillaries must be shielded. For this purpose and also for reducing the gas spaces in the two compartments containing the material $(15 \mathrm{mg}$ each), the double-chamber was filled with paraffin coloured with carbon black so that a gas space of $1.0 \mathrm{ml}$ is left in each compartment. The

*) Supported by a Grant in Aid from the Ministry of Education. 
structure of the chamber is such that the material in it is shielded from the light illuminating the two oil drops. In the experiment a very limited spot with a diameter of less than $1 \mathrm{~mm}$ in the middle of the connecting strand between the two compartments was illuminated with faint light for observation.

Simultaneous measurement of the motive force and respiration in the dark was made, first, when the material was in an atmosphere of $95 \% \mathrm{~N}_{2}+5 \% \mathrm{O}_{2}$ which served as control. After this was done a gas mixture of $95 \% \mathrm{CO}+5 \% \mathrm{O}_{2}$ was substituted by perfusion through two vents attached to each of the compartments.

One of the results of the experiment in the dark is shown in Fig. 1. The 25 minutes' record at the left half represents $\mathrm{O}_{2}$-uptake and motive

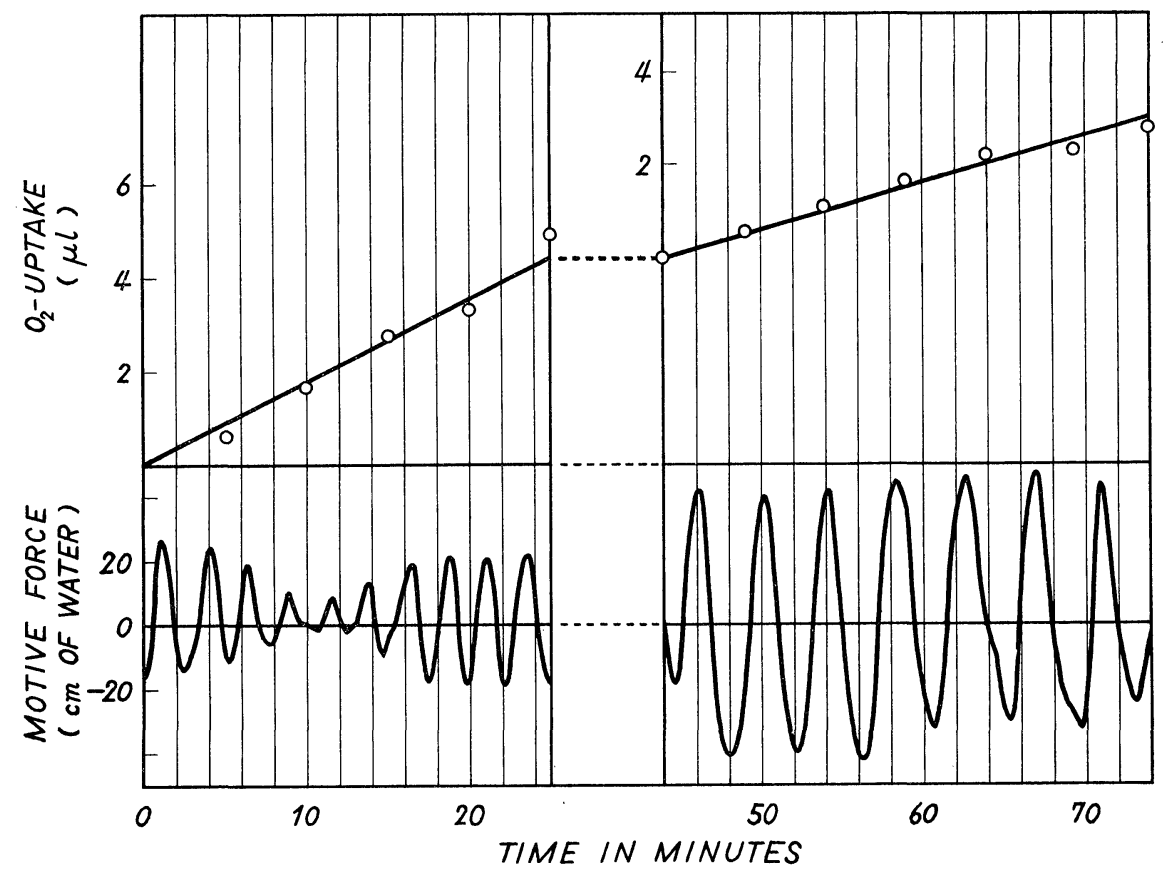

Fig. 1. $\mathrm{O}_{2}$-uptake and the motive force production of one and the same plasmodium in the dark under $95 \% \mathrm{~N}_{2}+5 \% \quad \mathrm{O}_{2} \quad\left(\mathrm{QO}_{2}=2.2 \mu \mathrm{l} / \mathrm{mg} / \mathrm{hr}\right)$ [left] and under the effect of $95 \% \mathrm{CO}+5 \% \quad \mathrm{O}_{2} \quad\left(\mathrm{Qo}_{2}=1.3 \mu \mathrm{l} / \mathrm{mg} / \mathrm{hr}\right)$ [right]. The amount of the plasmodium: $30 \mathrm{mg}$. Temp.: $19^{\circ} \mathrm{C}$

force production when the plasmodium was in the gas mixture of $95 \%$ $\mathrm{N}_{2}+5 \% \mathrm{O}_{2}$. The $\mathrm{Q}_{\mathrm{O}_{2}}$ in this case was $2.2 \mu \mathrm{l} / \mathrm{mg} / \mathrm{hr}$ on the dry weight basis. According to our previous report, ${ }^{5)}$ there is no difference both in $\mathrm{O}_{2}$-uptake and in motive force production whether the plasmodium is in the above mixture or in the atmospheric air, i.e. gas mixture of $80 \% \mathrm{~N}_{2}+20 \% \mathrm{O}_{2}$. On the right half of Fig. 1 we see how the respiration and motive force production were affected under the effect of 
$\mathrm{CO}$ in the dark. The curves here represent 30 minutes' records starting 44 minutes after the $\mathrm{CO}$ gas was admitted to the material. We see here that $\mathrm{O}_{2}$-uptake was reduced to about $60 \%\left(\mathrm{Q}_{\mathrm{O}_{2}}=1.3 \mu \mathrm{l} / \mathrm{mg} / \mathrm{hr}\right)$ of the control while the strength of the motive force, as represented by the amplitude of the curve, was augmented to about $200 \%$ of the control.

When the same material was exposed to light, the respiration was increased again with concomitant decrease in the motive force. But experiments along this line did not last long enough since the material which was kept in the dark frequently got opaque and gelated sooner or later upon exposure to light in the presence of CO gas. Once such a situation occurs, the motive force is no longer measurable. Thus we set up the condition of the experiment testing the effect of light upon $\mathrm{CO}$ action in the following manner.

b) Experiment in the light. The material in the double-chamber was illuminated with incandescent light of 2000 lux filtered through water in a cuvette, $5.5 \mathrm{~cm}$ thick, for 100-150 minutes before and during the measurement. Simultaneous measurement of both the motive force and respiration was done, as in the case of the experiment in the dark, first in the mixed gas of $95 \% \mathrm{~N}_{2}+5 \% \mathrm{O}_{2}$. After

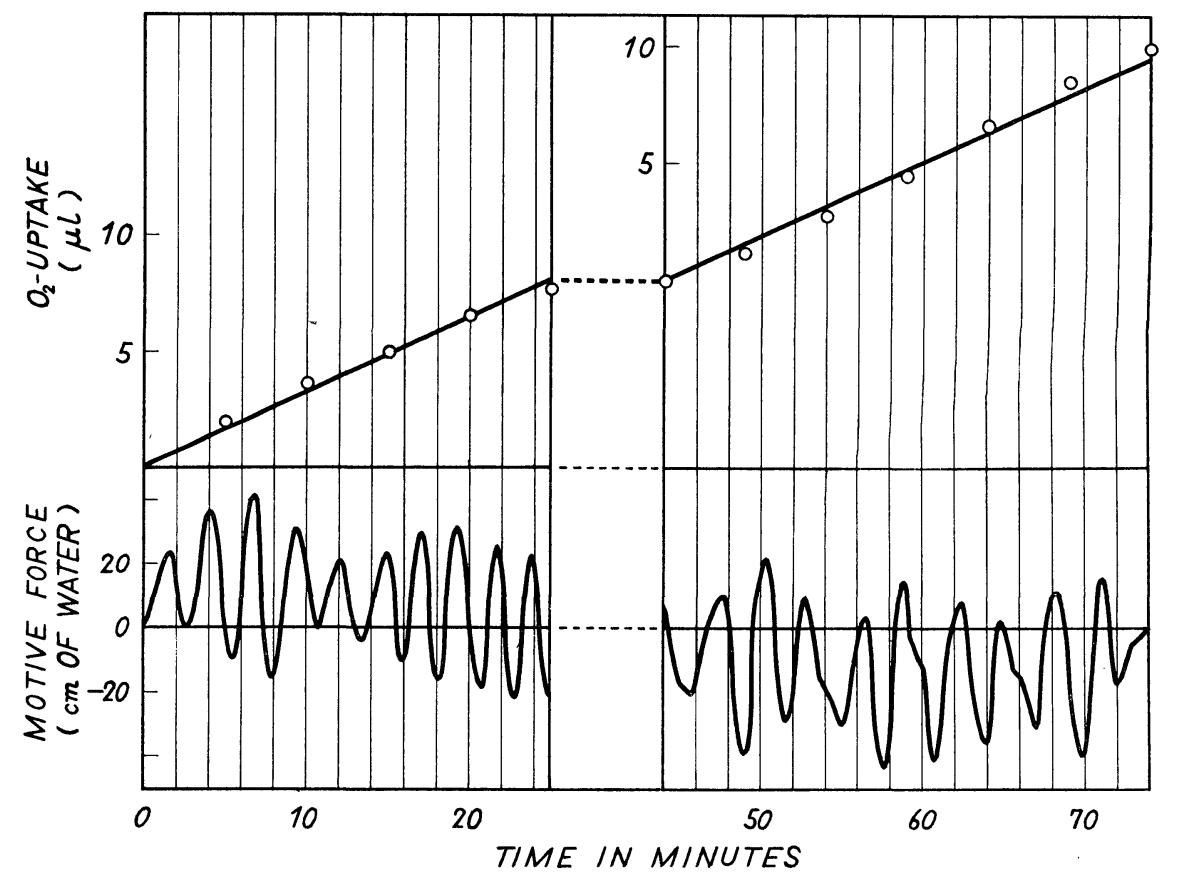

Fig. 2. $\mathrm{O}_{2}$-uptake and the motive force production of one and the same plasmodium in the light under $95 \% \quad \mathrm{~N}_{2}+5 \% \quad \mathrm{O}_{2}\left(\mathrm{Q}_{2}=3.8 \mu \mathrm{l} / \mathrm{mg} / \mathrm{hr}\right)$ [left] and under the effect of $.95 \% \mathrm{CO}+5 \% \mathrm{O}_{2}$ [right]. The amount of the plasmodium: $30 \mathrm{mg}$. Temp.: $20^{\circ} \mathrm{C}$ 
the measurement was conducted over a sufficient period of time under this condition, the gas was replaced with $95 \% \mathrm{CO}+5 \% \mathrm{O}_{2}$. The procedure is the same as in the case of the experiment in the dark except that the material is kept exposed to the light. Fig. 2 represents one of the results thus obtained. We understand from Fig. 2 that respiration remained the same before and after $\mathrm{CO}$ was applied $\mathrm{Q}_{\mathrm{O}_{2}}$ being both $3.8 \mu \mathrm{l} / \mathrm{mg} / \mathrm{hr}$ on the dry weight basis. The magnitude of the motive force shows likewise no appreciable change. In other words, in the presence of light $\mathrm{CO}$ gas has hardly any effect both on respiration and motive force production.

Experiments conducted under similar conditions were unanimous in that whenever $\mathrm{O}_{2}$-uptake was decreased under the effect of $\mathrm{CO}$ gas in the dark the motive force was increased invariably and that these influences upon $\mathrm{O}_{2}$-uptake and motive force production were not seen when the material was exposed to light. The response of the plasmodium to carbon monoxide in the dark is essentially similar to the response to cyanide ${ }^{6}$ both in regard to respiration and the motive force production. Here again, we have another example corroborating the fact that the motive force responsible for the protoplasmic streaming in the plasmodium increases when respiration is inhibited.

\section{References}

1) Allen, P. J., and Price, W. H.,: Amer. J. Bot., 37, 393 (1950).

2) Ohta, J.,: J. Biochem., 39, 489 (1954).

3) Ohta, J.,: Cytologia, 17, 300 (1952).

4) Kamiya, N., Abe, S., and Nakajima, H.,: Proc. Japan Acad., 33, 206 (1957).

5) Kamiya, N., Abe, S., and Nakajima, H.,: Proc. Japan Acad., 34, 530 (1958).

6) Kamiya, N., Abe, S., and Nakajima, H.,: Proc. Japan Acad., 33, 407 (1957). 